\title{
NOTES and LETTERS
}

\section{Monarch Butterflies in 2013}

ARDYTHE MCMASTER, Manitoba

I never discourage the milkweed plants that pop up in my garden, for I know that milkweed, hosts the regal Monarch butterfly. The finishing touch on my garden is always the sight of a Monarch or two fluttering among the flowers.

The summer of 2012 offered us many Monarchs. They arrived unusually early in the season, and set about their summer business. What fun to come upon some tiny Monarch hatchlings! Measuring hardly more than a quarter inch, they were nevertheless easy to identify in their tiny yellow, white and black stripes.

They did not remain tiny for long. They nibbled, and munched, and then chomped on their milkweed menu, (though the milkweed did not seem to mind), and in no time those Monarch larva had grown to a couple of inches in length.

Stepping outside one sunny morning, I saw that a sun ray had caught something shiny at the far end of the garden. I hurried over to investigate and there it was, the first Monarch chrysalis, gleaming bright gold and green from beneath its leaf.

That summer, many Monarchs soared and fluttered over my garden and our prairie.

But that was last year. This summer, 2013, I watched in vain for Monarchs. Not one until, on the sunny afternoon of September 29, a single one appeared briefly, then disappeared.

One single Monarch. It is disheartening to learn that 2013 brought a widespread, unexplained crash in Monarch population numbers across all of the range. I can only hope that better conditions, and my milkweed, will bring them back to my garden, to our prairie, and to their vast migration range.

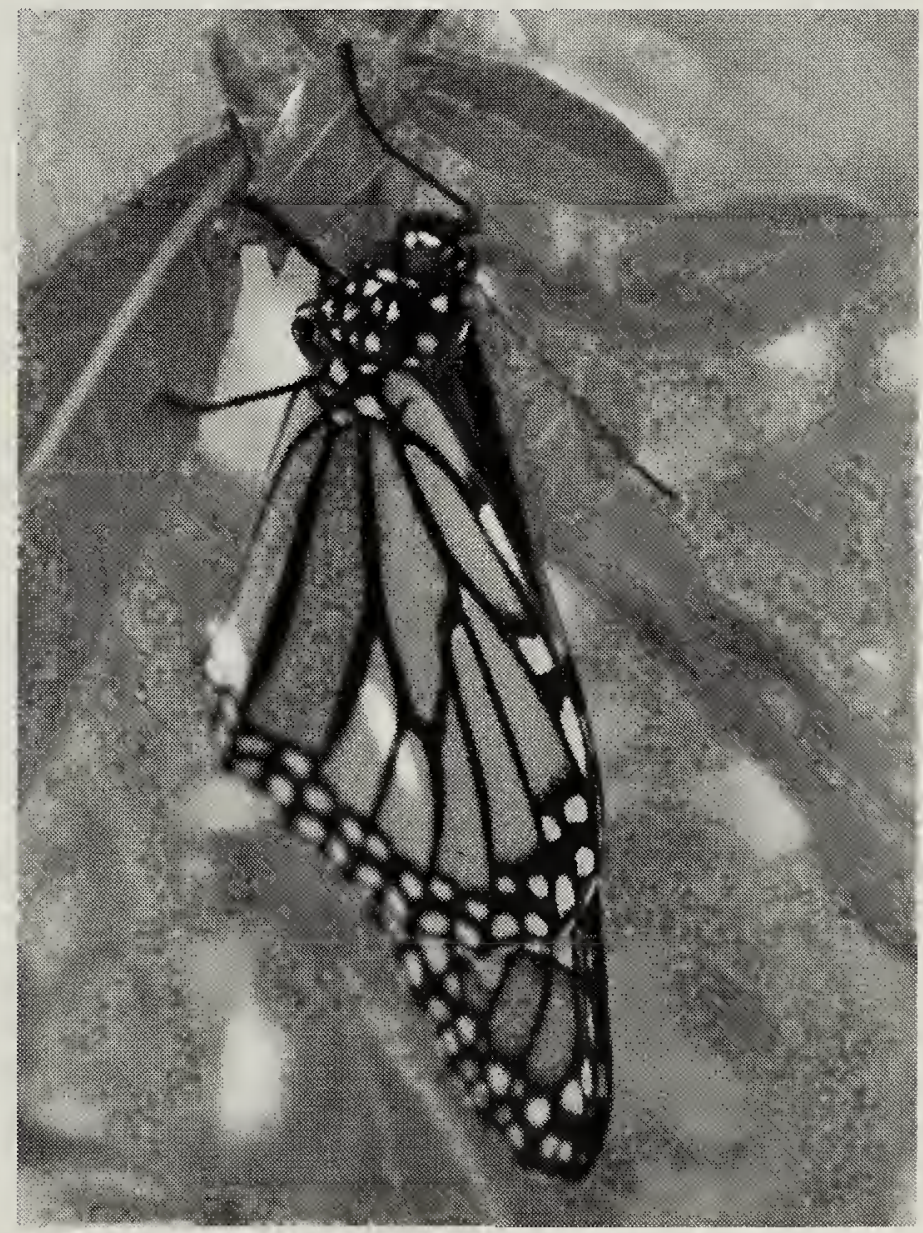

Monarch butterfly

- Kerry Hecker, LML NWA 